\title{
Don't aim too high: the potential costs of high aspirations
}

\author{
Astrid Matthey* \\ Nadja Dwenger**
}

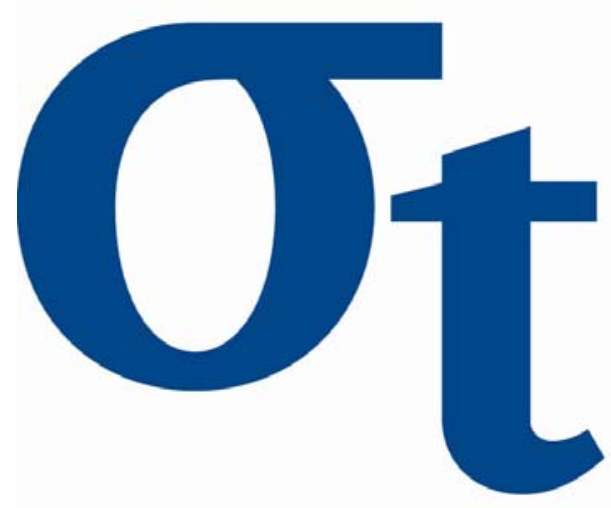

9)

$\forall$

6

* Max-Planck-Institute of Economics Jena, Germany ** DIW Berlin, Germany 


\title{
Don't aim too high: the potential costs of high aspirations
}

\author{
Astrid Matthey* and Nadja Dwenger ${ }^{\dagger}$
}

November 30, 2007

\begin{abstract}
The higher our aspirations, the higher the probability that we have to adjust them downwards when forming more realistic expectations later on. This paper shows that the costs induced by high aspirations are not trivial. We first develop a theoretical framework to identify the factors that determine the effect of aspirations on expected utility. Then we present evidence from a lab experiment on the factor found to be crucial: the adjustment of reference states to changes in expectations. The results suggest that the costs of high aspirations can be significant, since reference states do not adjust quickly. We use a novel, indirect approach that allows us to infer the determinants of the reference state from observed behavior, rather than to rely on cheap talk.
\end{abstract}

JEL classification: D11, D84, C91

Keywords: aspirations, reference state, expectations, individual utility, experiments

${ }^{*}$ Max-Planck-Institute Jena

${ }^{\dagger}$ DIW Berlin.

Corresponding address: Matthey@econ.mgp.de

The authors thank participants of seminars at Technical University Berlin, Humboldt University Berlin, University of Jena and University of Nottingham, as well as conference participants at the IMEBE 2007 in Malaga and the International Conference "Policies for Happiness" in Siena for helpful comments.

Matthey gratefully acknowledges the support by the Deutsche Forschungsgemeinschaft through SFB 649 'Economic Risk' and GK 1411 through part of this research. 


\section{Introduction}

Throughout our lives we have aspirations regarding future outcomes which are not based on detailed information. We have a perception of our planned career and future wealth without having reliable information on our own abilities, the abilities of others, or the market conditions prevailing in ten years time. We may also have a certain conception of our private life, without knowing whether we will meet a suitable partner, or be able to sustain a close relationship in case this is what we hope for.

When time passes by and we obtain better information, our aspirations often have to be updated. We may learn that we can expect a better or worse job than the one we aspired for, to earn more or less than we thought, or to have a more or less fullfilling relationship than we hoped for. If we adapt to these new expectations ${ }^{1}$ relatively quickly, initial aspirations do not influence the utility we derive from outcomes: We do not mind having a less prestigious job or earning less than we thought while young, or having a few more marriages than intended. If, however, we do not adapt quickly to new expectations, but keep on comparing outcomes to past aspirations, not meeting these aspirations will leave us disappointed. Then, entertaining high aspirations that are not supported by reliable information induces costs in expected utility, which may offset the positive effects of such aspirations on, e.g., motivation or utility from anticipation.

The purpose of this paper is to analyze to what extent we have to expect such costs. We first derive theoretically the impact of aspirations on utility. Although this identifies several factors that determine the costs of high aspirations, it shows that adaptation to new expectations plays a crucial role: If people adapt quickly, no costs must be expected, irrespective of other parameters.

As the next step we run a lab experiment to test whether people do indeed quickly adapt to new expectations. In particular, through analyzing observed behavior we can infer whether the states people compare their outcomes to, i.e., their reference states, adjust to changes in expectations during the experiment. The results suggest that this is not the case, implying that the costs induced by high aspirations are not trivial. Aiming high may hurt more than it helps.

Note that the adaptation we consider differs fundamentally from what Selten (1998) and Sauermann and Selten (1962) analyze in the Aspiration Adaptation Theory. In particular, we do not analyze the deliberate adaptation of aspirations to performance feedback, but the subconscious adaptation of reference states to changes in aspirations or expectations. This means that we analyze the utility of individuals, rather than the strategies of organizations, e.g., firms.

Although there seems to be broad agreement in the literature that utility from (or satisfaction with) a certain outcome does not only depend on the outcome itself, but also on what it is compared to, the details of this process are still little understood. For example, there are plenty of suggestions on what forms the comparison level or reference state for an outcome: one's own previous experiences

\footnotetext{
${ }^{1}$ We will denote plans and perceptions which are based on detailed knowledge of the relevant distribution as "expectations", while those that are based on only vague knowledge of the distribution as "aspirations". See section 2 for details. We will not discuss compound distributions, subjective distributions over distributions etc. in this paper.
} 
(status quo or habit formation, see, e.g., Campbell and Cochrane, 1999; Gomes and Michealides, 2003), the outcomes of relevant others (social comparison, e.g., Abel, 1990), one's aspirations (e.g. Simon, 1959; Ng and Wang, 2001; van Osch, van den Hout and Stiggelbout, 2006; Lopes and Oden, 1999, McBride, 2007), or one's expectations (e.g., Shalev, 2000; Koszegi and Rabin, 2006). However, little is known about what determines the relevance of these components for a certain situation or individual, or to what extend individuals can choose what forms their reference state.

As its contribution to this ongoing discussion, this paper focuses on the latter two components: It analyzes how initial aspirations influence expected utility when individuals form well-informed expectations later on. Unfortunately, in the literature there is no clear distinction between either aspirations and reference states (see, e.g., Huck et al., 2007; McBride, 2007), or aspirations and expectations (see, e.g., Selten, 1998 and Stutzer, 2004). Hence, some remarks about the terminology used in this paper seem warranted. First, we will use the term reference state to generally denote the state that an individual compares her existing state or outcome to. Aspirations, in contrast, are one component among others that may influence this comparison state. Some literature on aspirations defines the reference state more narrowly as one special case of the comparison level (e.g. $\mathrm{Ng}$ and Wang, 2001). Our choice has two reasons. First, "reference state" seems a more neutral term, which simply expresses this state's function as a comparison level for the definition of gains and losses. Second, previous research has credibly put forward components of the reference state, like habituation, which cannot naturally be subsumed under the concept of aspirations. Hence, aspirations in our paper are interpreted as an individual's plans and hopes, which are not based on detailed information. When the individual later receives detailed information, she forms expectations. More formal definitions of the two concepts are given in section 2 .

Second, we will use the term utility and take it as a proxy for individual well-being or happiness. We therefore abstract from problems like that of measuring "true" well-being (Kahneman et al., 2006), or individual failure to optimize well-being (Hsee and Hastie, 2006). Although this is a simplification, it seems an acceptable approximation in our setting.

Previous empirical and experimental analyses of the reference state have usually relied on survey studies (e.g. Stutzer, 2004). Since surveys have to rely on cheap talk, they potentially suffer from untruthful statements of the subjects, both intentionally and unintentionally. For example, people may want to appear less demanding than they are, or may perceive themselves as being less materialistic than they actually are. (On the implications of identity matters on individual decision making and utility, see, e.g., Akerlof and Kranton, 2000.)

In this paper we chose an alternative approach, which derives the determinants of the reference state from observed behavior. In particular, we measure subjects' risk attitude while controlling for their expectations and previous outcomes. Since previous research suggests a relation between feelings of loss and gain on the one hand, and risk attitude on the other (see, e.g., Kahneman and Tversky, 1979, Staw, 1976, Thaler and Johnson, 1990, Weber and Zuchel, 2005), this approach allows us to infer the factors influencing individuals' reference states from the 
factors that induce changes in their behavior towards risk. As a control, and in order to be able to compare the two methods, we also assess individuals' reference states and levels of satisfaction directly in a questionnaire, that is, as cheap talk.

The results of our experiment suggest that reference states indeed take time to adjust to expectations. Observed risk attitudes as well as self-reported reference states depend on both, initial aspirations and new expectations. This means that both approaches, the observed-behavior approach and the cheap-talk approach imply that individuals do not adapt quickly to new expectations. This in turn implies that high aspirations may lead to decreases in expected utility.

The remainder of the paper is organized as follows. Section 2 theoretically analyzes the impact of aspirations on utility. It shows that the adaptation of aspirations determines whether losses in utility can arise. The experiment to test this adaptation is described in section 3. Section 4 shows the results, while section 5 concludes.

\section{Theory}

\subsection{Aspirations}

Let $X \subset \mathbb{R}$ be the set of possible future outcomes of the individual, with $x$ as its elements. For example, $X$ may denote the income or consumption level the individual can achieve. $f(X)$ is the probability distribution on $X$.

The individual can form an aspiration $x_{A}$, where $x_{A}$ is one element of $X$. In particular, the aspiration is defined as the plan or perception an individual has regarding the element of $X$ she will receive in the future, while the information about the distribution on $X$ is vague. Due to this vagueness, an individual's aspiration can differ from the expected outcome that she infers from the information available. In particular, the aspiration can be influenced by different "biasing" factors, like social comparison (Stutzer, 2004), self-image (Nauta et al., 1998; Bandura et al., 2001, Pinquart et al., 2004), wishful thinking (Bryce and Olney, 1991) etc. These biases distinguish aspirations from expectations, which are formed when detailed information becomes available. Expectations are defined as unbiased, i.e., they correctly reflect the information available.

The relevant feature of aspirations that this definition captures is the individual's leeway in forming them. Although she may infer the distribution on $X$ from the information available, this information is vague enough for the individual's beliefs to deviate from the expected value of this distribution. ${ }^{2}$ This results in potential differences between aspirations and expectations. Then, the individual's beliefs have to adjust from aspirations to expectations when information becomes more detailed.

It should be noted that the focus of this paper, and the definition of aspirations differ from Selten's (1998) Aspiration Adaptation theory. First, Selten analyzes the adaptation of aspirations in a deliberate process of goal setting in organizations. For example, he analyzes how managers may choose a certain profit target.

\footnotetext{
${ }^{2}$ Whether the deviation can deliberately be influenced by the individual or is fully determined by the biasing factors, to our knowledge has not been well researched yet.
} 
In contrast, we analyze the adaptation of reference states when aspirations become expectations, or when expectations change due to new information. For example, a person who aimed at earning 200,000 EUR a year may realize that she will probably never earn more than 100,000 EUR. She then has to adjust her reference state to this expectation. This process, which must be expected to work mainly subconsciously, is analyzed in this paper. Second, Selten's aspirations are chosen from the set of expected feasible outcomes, i.e., they are unbiased expectations given some plan of action (e.g., profits given the chosen marketing strategy). In contrast, aspirations in our setup are individual and may be biased away from the expected value, e.g., by social comparison, self-image etc.

We formalize aspirations as "based on vague information and potentially biased" and expectations as "based on detailed information and unbiased" in the following way. When there is only vague information, the density function on $X$ as perceived by the individual is relatively flat, i.e., it assigns significant probability mass to the tails of the distribution. When more detailed information becomes available, the density function gets narrower, that is, the tails of the distribution receive less probability mass.

An individual's aspiration $x_{A}$ is then defined as being an element of $X$ such that the cumulative distribution function $F_{X}$ assigns a probability of at least $\rho$ to outcomes at least as good as $x_{A}$ :

$$
1-F_{X}\left(x_{A}\right) \geq \rho
$$

$\rho$ forms the cutoff probability down to which the individual "believes her aspirations". It ensures that the probability of reality falling behind the individual's aspirations is not too high, with "too high" being determined by the individual. The vaguer the information, the more probability mass is located at the tails, and hence the larger is the range of outcomes for which inequality (1) is fulfilled. The individual has more leeway for her aspirations to be influenced by biasing factors like social comparison or self-image.

If the density function gets narrow enough such that the best possible realization the individual can aspire for is below $E(X)+\Delta$, with $\Delta$ reflecting the notion of "detailed information", the individual's aspiration turns into an expectation. For $\Delta=0$, the individual's aspirations are only called expectations if they match the expectation of $X$, i.e., if they are correct given the information available (see figure 1). This is the case we consider here. However, the general argument can be extended to the case of $\Delta>0$, i.e., "roughly correct" expectations.

Given these definitions, an individual's aspirations can be altered by changes in the biasing factors or their relative weight, or by changing the cutoff probability. "Less ambitious" aspirations, for example, would be translated into a higher $\rho$, that is, aspiring for a more likely, though possibly less preferred outcome.

Consider now the timing. There are three periods. In $t=1$ the individual receives only vague information and forms aspiration $x_{A}$ within the range specified by (1). From this aspiration she derives anticipatory utility $u^{a}\left(x_{A}\right)$, that is, utility from looking forward to the aspired outcome (see e.g., Caplin and Leahy, 2001). In $t=2$ the individual receives more detailed information and corrects her aspiration $x_{A}$ to the true expectation $E(X)$. She again derives anticipatory utility from this, $u^{a}(E(X))$. Finally, in $t=3$ the individual receives outcome $x$ as a realization of 
$X . x$ induces absolute, that is, reference-independent utility $u(x)$ and relative, that is, reference-dependent utility $v(x \mid r)$.

This yields the individual utility function

$$
U=\underbrace{u^{a}\left(x_{A}\right)}_{t=1}+\underbrace{u^{a}(E(X))}_{t=2}+\underbrace{u(x)+v(x \mid r)}_{t=3}
$$

which is based on the following simplifying assumptions:

A1: Anticipatory utility is reference-independent (Matthey (2006) shows that it is reference-dependent, but including this would not influence our main argument.) A2: When deriving anticipatory utility, individuals consider only the absolute utility in $t=3$, i.e., they do not anticipate reference states. ${ }^{3}$ Further, they derive utility only from anticipating the outcomes to be realized in $t=3$, not from anticipating in $\mathrm{t}=1$ the anticipatory utility in $\mathrm{t}=2$.

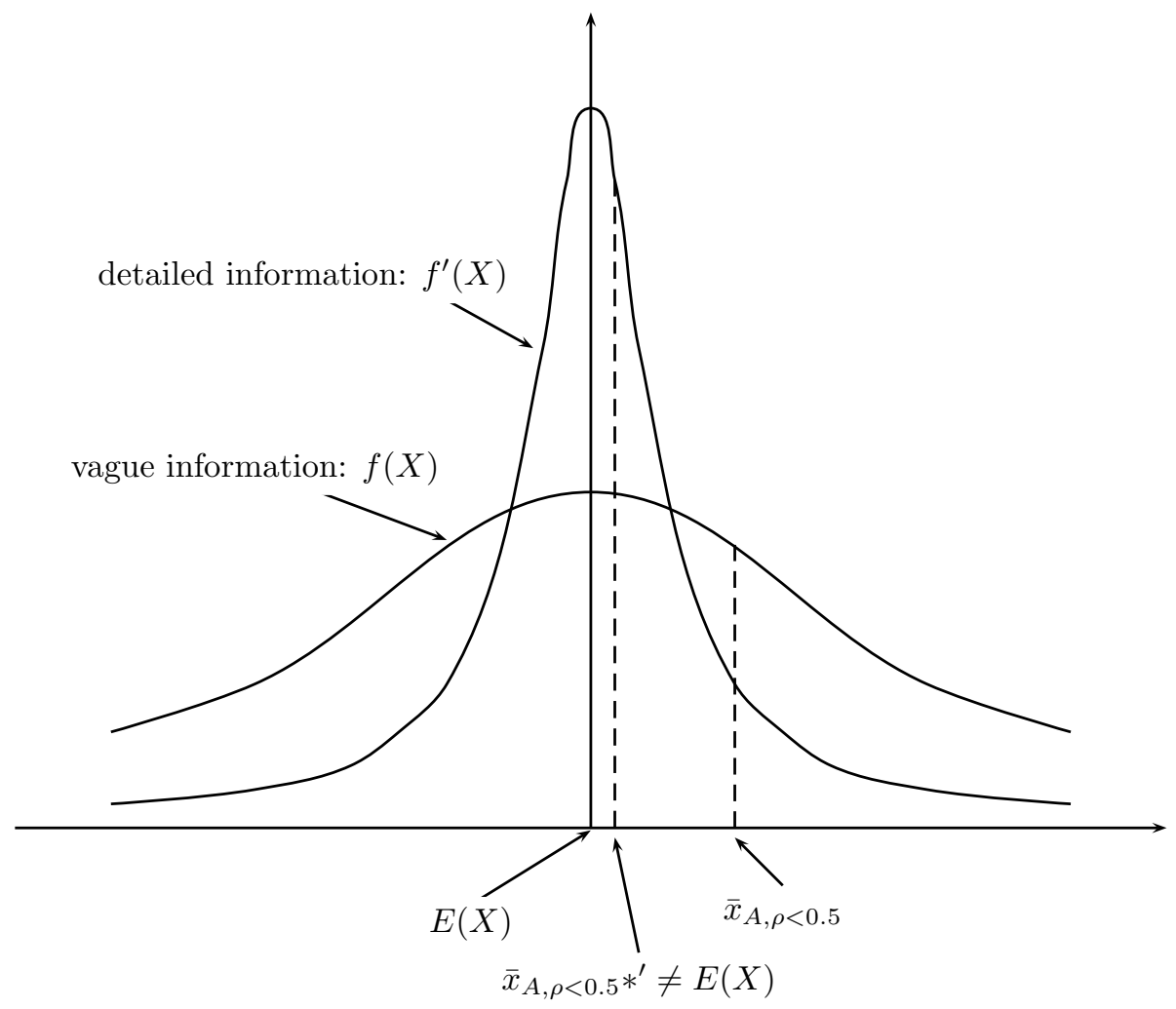

Figure 1: Example of aspirations and expectations: the highest possible aspiration level $\bar{x}_{A}$ is determined by the cutoff probability $\rho<0.5 . \bar{x}_{A}^{\prime}$ is determined by the same cutoff probability $\left(F_{X}\left(\bar{x}_{A}\right)=F_{X}^{\prime}\left(\bar{x}_{A}^{\prime}\right)\right)$, but more detailed information. Hence, $\bar{x}_{A}^{\prime}<\bar{x}_{A}$. However, $\bar{x}_{A}^{\prime}$ is still incorrect: $\bar{x}_{A}^{\prime}>E(X)$, that is, aspirations are still biased away from the true expectation.

\footnotetext{
${ }^{3}$ Note that there is no evidence on whether individuals actually include reference states in anticipations or not.
} 


\section{$2.2 \quad$ Reference state}

The reference-dependent utility an individual derives from an outcome $x$ has been specified by Kahneman and Tversky (1979) as $v(x \mid r)$, where $r$ is the reference that $x$ is compared to. In the simplest case, $r$ can be conceptualized as a singleton. For example, in a model of habit formation, $r$ could be the weighted average of the outcomes an individual received in the past. More generally, $r$ can be modeled as a vector, e.g. of the individual's expectations, her aspirations, relevant others' outcomes etc.

In our setup the individual receives the outcome in $t=3$, and compares it to her reference state in $t=3, r_{3}$. This reference state is formed in $t=1$ and $t=2$ when the individual first forms aspirations $x_{A}$ and then expectation $E(X)$. Since this paper focuses on the influence of aspirations and expectations, we will ignore all other factors that may influence the reference state like social comparison or habituation. However, we allow these factors to influence the reference state indirectly by influencing aspirations.

The timing is as follows. The individual enters each period with a certain reference state. During a period she first receives new information (if there is any). Then she forms aspirations or expectations, depending on the quality of the information. These factors then influence her reference state in the next period.

This sequence reflects the fact that reference states must be expected to require some positive amount of time for adjustment, i.e., reference states depend on the past, rather than the present. Letting the length of a period and the time between periods converge to zero, this sequence can account for all specifications of the reference formation process. ${ }^{4}$

The reference state in $t=3$ can then be written as a function of the reference state in $t=2, r_{2}$, and the individual's aspirations and expectations:

$$
r_{3}=r_{3}\left(r_{2}, x_{A}, E(X)\right)
$$

Since in our simple setup $r_{2}$ can only be influenced by $x_{A}$, this reduces to

$$
r_{3}=r_{3}\left(x_{A}, E(X)\right)
$$

To further simplify the theory, we will write the reference state in $t=3$ as being formed by some linear combination of the two influencing factors (and drop the index):

$$
r=a x_{A}+(1-a) E(X) \quad \text { with } \quad a \in[0,1]
$$

The parameter $a$ denotes the impact of aspirations in $t=1$ on the reference state in $t=3$ when the individual has formed new expectations in $t=2$. If the reference state adjusts quickly to new expectations, $a=0$. If $a \neq 0$, aspirations continue to influence the reference state for a significant period of time even after detailed information has led to the formation of new expectations.

\footnotetext{
${ }^{4}$ In the case of a continuous model, the present disappears, and reference states can only possibly depend on the past. For expositional reasons, however, we develop our theory in discrete time.
} 


\section{$2.3 \quad$ Effect of aspirations on utility}

High aspirations may increase the individual's motivation to work hard, and hence enable her to achieve better outcomes. In addition, aiming high may have a positive signalling effect on others, which by inducing support, trust etc. may also increase the individual's expected outcome. In order to account for such effects, we assume the following: If the aspiration $x_{A}$ induces the cumulative distribution function $F_{X}$ over $X$ and another aspiration $x_{A}^{\prime}$ induces the cumulative distribution function $G_{X}$ over $X$, then $F_{X}$ first order stochastically dominates $G_{X}$ if and only if $x_{A}>x_{A}^{\prime}$ (and the support of $X$ is fixed). We will call this the motivation effect:

$$
F_{X}(x) \leq G_{X}(x) \quad \forall x \quad \Longleftrightarrow \quad x_{A}>x_{A}^{\prime}
$$

In words, when aspirations are higher, the individual achieves an outcome distribution which is at least as good as when aspirations are lower. In order to reflect reality, however, we will assume the productivity of motivation (and signalling etc.) to be subproportional: an increase of one unit in $x_{A}$ leads to an increase in $E(X)$ of less than one unit. This also implies that if aspirations increase from $x_{A}^{\prime}$ to $x_{A}$, and the motivation effect changes the distribution function from $G_{X}$ to $F_{X}$, the old cutoff probability $\rho^{\prime}$ associated with aspirations $x_{A}^{\prime}$ and induced by $G_{X}$ is higher than the new cutoff probability $\rho$ associated with aspirations $x_{A}$ and induced by $F_{X}$. Meeting higher aspirations is never more likely than meeting lower aspirations: although higher aspirations increase the expected outcome, the effect is never as large as the increase in aspirations that triggered it.

It should be noted that the positive effect of high aspirations on expected outcomes is not the focus of this paper. It is included in the theory in order to provide a more comprehensive picture of the influences of aspirations on utility, and to show that in spite of this positive effect a negative net effect of high aspirations can arise.

Including the specification of the reference state and the motivation effect, we obtain the individual's expected utility over periods $t=1$ to $t=3$ as: ${ }^{5}$

$$
\begin{aligned}
E(U) & =u^{a}\left(x_{A}\right)+u^{a}(E(X))+\int_{x} u(x) d F_{X}+\int_{x} v\left(x \mid a x_{A}+(1-a) E(X)\right) d F_{X} \\
= & u^{a}\left(x_{A}\right)+u^{a}(E(X))+\int_{x} u(x) d F_{X}+ \\
& +\int_{\underline{x}}^{r} v\left(x \mid a x_{A}+(1-a) E(X)\right) d F_{X}+\int_{r}^{\bar{x}} v\left(x \mid a x_{A}+(1-a) E(X)\right) d F_{X}
\end{aligned}
$$

where $\underline{x}$ and $\bar{x}$ denote the lowest and highest outcome in the support of $F_{X}$, respectively, and $v(x \mid r>x)$ differs from $v(x \mid r<x)$ by the individual's extend of loss aversion. The individual's optimal aspirations are then given by

$$
\frac{\partial E(U)}{\partial x_{A}}=\frac{\partial u^{a}\left(x_{A}\right)}{\partial x_{A}}+\frac{\partial u^{a}(E(X))}{\partial x_{A}}+\frac{\partial \int u(x) d F_{X}}{\partial x_{A}}+\frac{\partial \int_{x} v(x \mid r)}{\partial x_{A}}=0
$$

\footnotetext{
${ }^{5}$ This utility is expected since even with full information $X$ is stochastic.
} 
Due to the motivation effect we get that

$$
\frac{\partial u^{a}\left(x_{A}\right)}{\partial x_{A}}>0 \quad, \quad \frac{\partial u^{a}(E(X))}{\partial x_{A}}>0 \quad \text { and } \quad \frac{\partial \int u(x) d F_{X}}{\partial x_{A}}>0 .
$$

This means that there only exists a local optimum if $\frac{\partial \int_{x} v(x \mid r)}{\partial x_{A}}<0$. Otherwise, aspirations should be as high as possible in order to maximize the motivation effect and anticipatory utility. Accordingly, only if the effect of an increase in aspirations on expected relative utility is negative, can an increase in aspirations lead to a decrease in utility. Hence, if we can rule out a negative effect of $x_{A}$ on $\int_{x} v(x \mid r)$, no costs of high aspirations on individual utility must be expected.

The effect of an increase in aspirations on relative utility has two opposing components. First, similar to the effect on $u^{a}$ and $u$, the new distribution function dominates the old one as the result of the motivation effect and by this increases expected utility:

$$
\frac{\partial \int v\left(x \mid a x_{A}+(1-a) E(X)\right) d F_{X}}{\partial E(X)}>0
$$

Second, for $a>0$, an increase in $x_{A}$ increases the reference state, which reduces expected utility. ${ }^{6}$ For outcomes above the increased reference state utility decreases but is positive, for outcomes between the original and the increased reference state former gains turn into losses, while for outcomes below the original reference state existing losses become even larger. Hence,

$$
\frac{\partial \int v\left(x \mid a x_{A}+(1-a) E(X)\right) d F_{X}}{\partial r}<0
$$

Accordingly, the net effect of an increase in aspirations on relative utility is ambivalent: On the one hand, utility is increased by the motivation effect. On the other, it is decreased by the influence of initial aspirations on the reference state and by the degree of loss aversion (the difference in utility functions for losses and gains). However, if $a=0$, i.e, reference states quickly adjust to new expectations, relative utility is zero, and the effect of high aspirations on expected utility is unambiguously positive (no local optimum).

The question whether the reference state quickly adjusts to new expectations, i.e., whether $a=0$, is addressed by the experiment described in the next section. This shows whether high aspirations can lead to losses in utility.

\section{Experiment}

\subsection{Design}

The experiment consisted of four stages that were played once by each subject. In the invitation to the experiment it was written that the experiment would last about one hour and that participants would earn 12 Euro on average.

\footnotetext{
${ }^{6}$ The increase in $x_{A}$ also increases the reference state through increasing $E(X)$, but by definition of $r$ this effect never increases $r$ above $E(X)$.
} 
At the first stage, subjects stated a price for which they would have been prepared to abstain from the experiment. This serves as a proxy for their initial aspirations, and is denoted with ASP. The price was assessed through an interval method: As the first step, all subjects were asked whether they would abstain from the experiment if they instead received 15 Euro, but had to stay in the lab. Those who preferred the money were offered a lower price next. Those who preferred to take part in the experiment were offered a higher price next. This method was continued until subjects had specified their preferences up to one Euro cent. The interval method was explained in detail in the instructions, and a quiz ensured that all students had understood it. It was used for all prices we assessed during the experiment. It was also clearly stated that at some stages the assessed prices would not be paid out. If they were to be paid out, this was clearly indicated before the respective decision.

At the second stage, subjects were informed that they would later participate in a lottery. Half of the subjects received a lottery that would pay either 10 or 12 Euro with equal probability. The other half received a lottery that would pay either 1 or 3 Euro with equal probability. From this they could easily calculate the expected payoffs from their lotteries, EPL1. Subjects did not know what lottery the other participants received, or whether they received a lottery at all. After all subjects had learnt the features of their lottery, they had to perform a logical task. This task - completing series of numbers - lasted for 10 minutes. It was included in order to give the participants time to adjust their reference state to the expected payoff from the lottery they would take part in. Then they were asked for their certainty equivalent of the lottery they had received. From this we calculated the risk premium, $R P 1$, as the difference between expected payoff and certainty equivalent. ${ }^{7}$ Afterwards, the lotteries were played out and subjects received their payoffs, PAYL1, i.e., 1, 3, 10 or 12 Euro. This determined their nominal loss or gain, GoLL1: Individuals who received either 1 or 10 Euro lost relative to the expected payoff from their lottery, while individuals who received either 3 or 12 Euro won. Note that for this lottery certainty equivalents were not paid out.

At the third stage, subjects received a second lottery, which was the same for all. In this lottery, subjects would either have to pay 1 Euro from their previous payoffs or be paid 7 Euro extra with equal probability. ${ }^{8}$ We then assessed the subjects' certainty equivalent for this second lottery. The risk premium indicated by this choice is denoted RP2. Next, we used a Becker-DeGroot-Marshak mechanism to determine whether subjects would receive their certainty equivalent or the payoff from the lottery. The participants who took part in the lottery then flipped a coin, which determined their payoff. The others received their certainty equivalent. The payoff from the second lottery, PAYL2, was then added to the one from the first lottery.

Finally, at the fourth stage we asked our subjects, which payoff from the experiment they would have been satisfied with. This payoff is used as a (cheap talk)

\footnotetext{
${ }^{7}$ Terms like "certainty equivalent", "price" etc. were not used in the experiment. See the appendix for a translated version of the instructions.

${ }^{8}$ That subjects can make nominal losses here is not a problem since all subjects received the same lottery, and risk attitudes were analyzed relative to other subjects, rather than in absolute terms.
} 
proxy for their reference state at the end of the experiment, $R E F$.

After the experiment had ended subjects filled in a questionnaire. There, they were asked how satisfied they had felt with their payoff from the first lottery (SatisfactionL1). As usually, we also collected data on age, gender, subject of study and previous experience with experiments.

48 students of either Technical University Berlin or Humboldt University Berlin participated in the experiment. The sessions took place at Technical University Berlin in December 2006. The software used to conduct the experiments was z-tree (Fischbacher, 1999).

\section{$3.2 \quad$ Hypotheses}

The design of the experiment can be interpreted in terms of the theory as follows: $t=1$ is the time when people enter the lab. At that moment they have already formed aspirations regarding their payoff from the experiment. Although we did give our subjects some information on the expected payoff from the experiment (12 EUR), aspirations as indicated by ASP differ widely. There are several possible reasons for that. First, people may not have noticed the information in the invitation regarding the expected payoff and instead derived their aspirations from some more general distribution. Second, they may have discounted the relevance of the information as being general information regarding the experiments that take place in the lab. Third, in the months before our experiment, several other experiments took place in the lab. Our participants may have participated in these experiments or may have heard from others who participated, and then extrapolated from average payoffs there. Forth, since the payoff from the experiment is uncertain when ASP is assessed, people may subtract a risk premium from their true aspirations. Fifth, the amount people state may include compensation for the utility they would derive from their participation in the experiment, that is, the fun of gambling. ${ }^{9}$

$t=2$ is the time when subjects receive information on the lottery they are going to participate in. The duration of the logical task is the period between $t=2$ and $t=3$, when reference states have time to adapt to the change from the individual's initial aspirations to the new expectations. Although this time is not too long (10 minutes), it was not short relative to the overall duration of the experiment (about $1 \mathrm{~h}$ ) or in relation to the amount of money involved. Further, due to some other tasks (e.g., determination of the certainty equivalent) the true time between forming expectations about the lottery and actually receiving the payoff was about 15 minutes. Finally, PAYL1 is the individual's outcome in $t=3$.

The second lottery in the experiment serves to measure the risk attitudes of the individuals after the first lottery, in order to infer the variables that influence their reference states. In particular, we want to know whether ASP and EPL1 influence the reference states, that is, individuals' risk attitudes. This step warrants some more explanation.

\footnotetext{
${ }^{9}$ For some people, this utility may have been negative, if they enjoy writing emails or reading a book more than participating in the experiment.
} 
Previous research implied that people's risk attitude depends on whether they are in the domain of losses or gains. In different contexts, individual's have been found to react differently to risk, depending on whether they have previously made losses or gains, or depending on whether they expect to make losses or gains. Staw (1976) observed behavior he calls "escalation of commitment", where losses in past situations lead to higher risk taking than gains. In similar, i.e., sequential situations, Thaler and Johnson (1990) find the opposite: after making gains, people become more risk averse, a behavior the authors term the "housemoney effect". A recent study by Weber and Zuchel (2005) indicates that the opposing effects may arise as a result of different frames of the decision situation. This would also be consistent with the finding of Kahneman and Tversky (1979) that when facing losses, people become more risk loving than when facing gains.

What these results have in common is that depending on whether people experience/expect a loss or a gain, they react differently to risk. Hence, the factors that influence people's sentiment of loss and gain also influence their risk behavior. This is what matters for our approach. Any sentiment of loss or gain depends on three factors: First, a person's actual payoff. Second, her reference state. Together, these form the "objective" gain or loss. Third, her individual experience of this objective gain or loss, i.e., her degree of loss aversion. This forms her "subjective" gain or loss, that is, her utility from winning or losing. In the experiment, the objective gain or loss in $t=3$ is determined by the subjects' payoffs PAYL1 and their reference states. Their subjective gain or loss is approximated by asking for their satisfaction with the outcomes of the lottery, SatisfactionL1. Note that since 'SatisfactionL1' was only assessed at the end of the experiment, it may suffer from hindsight bias. This had to be accepted since asking for subjects' satisfaction during the experiment would have focused their attention on their level of satisfaction, which could have biased the results.

From this we can derive the following prediction: If the individual's reference state in $t=3$, i.e., when the first lottery is played out, is determined by the expected payoff from this lottery, her feeling of loss or gain depends on whether she gets the high (3 or 12 Euro) or the low (1 or 10 Euro) payoff in her respective lottery. Accordingly, her risk attitude in the second lottery, RP2, should be influenced by whether she won or lost within her respective lottery (GoLL1). If, however, the individual's reference state in $t=3$ is determined by her initial aspirations, whether she experiences a loss or a gain depends on whether she gets a high (10 or 12 Euro) or a low (1 or 3 Euro) payoff relative to her aspirations. In this case, her risk attitude in the second lottery should be influenced by her aspirations and by whether she received the good or the bad lottery, i.e., the expected payoff from her lottery.

Our hypotheses can then be formulated as follows:

Hypothesis 1: The risk premium in the second lottery does not depend on whether subjects received a loss or a gain in the first lottery, relative to the expected payoff from this lottery.

If Hypothesis 1 is rejected, the new expectations influence people's reference state in the 10 minutes of the logical task. This would mean that there is at least some adaptation to new expectations within reasonable time, i.e., $a<1$. 
Hypothesis 2: The risk premium in the second lottery does not depend on subjects' initial aspirations and their expected payoff in the first lottery.

If Hypothesis 2 is rejected, people's initial aspirations continue to influence their reference states even after the 10 minutes of the logical task. This would mean that adaptation to new expectations requires considerable time, i.e., $a>0$.

Note again that the link between people's reference states and the hypotheses is based on the assumption of a relationship between feelings of gain and loss and risk attitude. Although the details of this link are not crucial for our argument, some relation has to be assumed.

Finally, asking subjects at the very end for the amount they would have found "satisfactory" served as a control for the cheap talk method of assessing reference states. In contrast to the initial aspirations, this amount includes neither a risk premium nor a gambling premium. In this sense, it is a cleaner proxy for the reference state at the end, than ASP is for the aspirations at the beginning. However, since subjects already knew their payoffs at the time we assessed REF, some endowment effects may have been included, and hindsight bias may be present.

\section{Results}

To test our hypotheses, we regress the risk premium of the second lottery on the individuals' initial aspirations (ASP), the difference between these aspirations and the expected payoff in the first lottery (DIFFL1), the indicator of nominal gains and losses in the first lottery (GoLL1), the risk premium in the first lottery (RP1) and the level of satisfaction with the first lottery (SatisfactionL1), see table 1 (OLS regression with robust standard errors).

\begin{tabular}{|l|r|l|}
\hline RP2 & coefficient & p-value \\
\hline \hline ASP & -0.144674 & $0.034^{* *}$ \\
\hline DIFFL1 & 0.093254 & $0.085^{*}$ \\
\hline GoLL1 & -0.884621 & $0.082^{*}$ \\
\hline RP1 & 0.613952 & 0.213 \\
\hline SatisfactionL1 & -0.636353 & $0.019^{* *}$ \\
\hline Experience & -0.779053 & $0.076^{*}$ \\
\hline Econ & -0.509445 & 0.277 \\
\hline constant & 0.641807 & 0.688 \\
\hline
\end{tabular}

Table 1: Regression for the risk premium of the second lottery (robust standard errors, R-squared $=0.2691$ ).

In DIFFL1 we include the expected payoff EPL1 rather than the received payoff PayL1 in order to avoid that the level of the payoff (high or low) enters the regression together with losses and gains in the lottery. Hence, the difference between EPL1 and ASP is a proxy for the objective gain or loss that an individual receives, without accounting for losses and gains relative to the expected payoff from the lottery. We also include the subjects' stated satisfaction with the payoff 
from the first lottery (SatisfactionL1). ${ }^{10}$ As explained above, given a certain reference state and level of payoff in the first lottery, i.e., given an objective loss or gain, due to different degrees of loss aversion not all individuals will experience the same feeling of loss or gain. But this subjective loss or gain must be expected to influence behavior.

We include the risk premium of the first lottery, RP1, to account for the individual's general risk attitude. Furthermore, we test whether subjects who have already taken part in an experiment before (Experience) react differently from those who have not. As our subject pool contains some students of economics, we also control for this characteristic (Econ).

We find that the initial aspirations (ASP), the difference between aspirations and expected payoff (DIFFL1), the satisfaction with the first lottery (SatisfactionL1) and the nominal gain or loss (GoLL1) are relevant for the determination of the risk premium in the second lottery and hence for the reference state. This means that Hypothesis 1 and Hypothesis 2 can both be rejected (at the $10 \%$ and $5 \%$ significance level, respectively). Accordingly, our results suggest that $0<a<1$.

Note that the coefficient of the risk premium of the first lottery is not significant. This is presumably due to the fact that part of the general risk attitude is captured in ASP, which dilutes the impact of RP1. The coefficient of the subjects studying economics is not significant either; hence, we do not have to worry about this group. Experience with experiments seems to play a role, though, by slightly decreasing individuals' risk aversion.

Consider now the second approach to understanding how the reference state changes during the experiment, i.e. the assessment of REF through cheap talk at the end of the experiment (see table 2).

\begin{tabular}{|l|r|l|}
\hline REF & coefficient & p-value \\
\hline \hline ASP & 0.396218 & $0.000^{* * *}$ \\
\hline PayL1 & 0.414909 & $0.000^{* * *}$ \\
\hline PayL2 & 0.336095 & $0.070^{*}$ \\
\hline sex & -3.259390 & $0.017^{* *}$ \\
\hline constant & 3.534700 & $0.025^{* *}$ \\
\hline
\end{tabular}

Table 2: Regression for the final reference state (robust standard errors, R-squared $=0.4659)$.

The results support those of the first approach. The initial aspirations continue influencing the reference state at the end, but it is also effected by the payoffs received during the experiment. The second point, however, must be interpreted with care. Since REF was assessed after the subjects had learnt their payoffs, endowment effects may play a role. It is therefore hard to distinguish whether the expectations regarding their final payoffs have influenced individual's reference state, or whether the payoffs they received on paper (not in cash yet) have led to an endowment effect. However, the highly significant coefficient of ASP shows clearly that $a>0$ when reference states are assessed through cheap talk.

\footnotetext{
${ }^{10}$ Although this may potentially induce a problem of endogeneity.
} 
This latter result is also supported by the analysis of the subjects' level of satisfaction with payoffs from the first lottery (table 3 ).

\begin{tabular}{|l|r|l|}
\hline SatisfactionL1 & coefficient & p-value \\
\hline \hline ASP & -0.090473 & $0.002^{* * *}$ \\
\hline DIFFL1 & -0.088262 & $0.001^{* * *}$ \\
\hline GoLL1 & -1.206697 & $0.000^{* * *}$ \\
\hline constant & 3.609754 & $0.000^{* * *}$ \\
\hline
\end{tabular}

Table 3: Regression for the satisfaction with the payoffs from the first lottery (robust standard errors, R-squared $=0.4685$ ).

The regression shows that the satisfaction level after the first lottery is again determined by the individual's initial aspirations, the difference between these aspirations and the expected payoff from their lottery, and whether they gained or lost in their respective lottery. It is also strongly influenced by the constant, i.e. individuals seem to have an inherent level of satisfaction that is relatively inert and cannot be explained by our regressors. This means that they react differently to nominal losses or gains, e.g., due to different degrees of loss aversion, which explains the influence of SatisfactionL1 in the regression for RP2.

In summary, the experiment provides strong evidence against the hypothesis that aspirations do not influence reference states after new expectations are formed, i.e., we find that $a>0$. It also gives some evidence that people do adjust their reference states to new expectations, although at a moderate speed: $a<1$.

\section{Conclusion}

Aiming high and working hard is the chosen path of many people in industrialized countries. This paper shows that there may be a cost involved in this approach.

We first show theoretically that if people do not quickly adapt to new expectations, high aspirations can induce losses in expected utility. Although other parameters can be relevant for the size of the reduction in utility, whether adaptation happens quickly is shown to determine whether there is potential for losses or not.

As the next step, we use a lab experiment to test whether reference states indeed adapt quickly when expectations change. The results indicate that this is not the case, which implies that there is a potential for significant losses in utility when people maintain high aspirations.

Our results also show that additional research concerning the formation of reference states is needed, as reference states cannot be explained with expectations alone. Since aspirations are found to influence reference states beyond the formation of expectations, further research into the factors that influence aspirations is required. 


\section{Appendix}

\section{Instructions}

The following experiment is part of a research project which is financed by the Deutsche Forschungsgemeinschaft (German Research Foundation). It aims at analysing economic decision behaviour.

You can earn a considerable amount of money within this experiment. The amount

of money depends on your decisions. Hence, it is very important to read these instructions carefully and thoroughly.

Please note that these instructions are only intended for you. You are not allowed to circulate any information to other participants. By the same token you are not allowed to talk to other participants during the whole experiment. If you have any questions please raise your hand. We will then pass by and answer your question. Please do not ask your question(s) aloud in any case. If you violate these rules we are forced to cancel the experiment.

\section{Procedure}

The experiment lasts for about $60 \mathrm{~min}$. It consists of several parts. In each of these parts you solve problems or make decisions. In each case, the respective decisions and problems will be carefully explained on the screen. Please note that your experiment's payoff does not only depend on your decisions. It is also influenced by random decisions made by the computer.

Not all of your decisions influence the amount of money that is paid out to you at the end of the experiment. If the decisions' results are paid out this is explicitly announced before you make these decisions. The other decisions and problems are not relevant for your payoff.

All figures in the decisions that are relevant for your payoff are given in Euro. They are paid out to you in exactly the given amount at the end of the experiment. Additionally, you receive 3 Euro for your participation.

\section{Lotteries}

Two times in the experiment you can take part in a lottery. You receive payoffs from these two lotteries. In each of the two lotteries there are two different payoffs, a higher and a lower one. In each case, you receive only one of these payoffs. Which payoff you receive depends on chance. The chance to receive the higher payoff is as big as the chance to receive the lower payoff. This can be visualised as follows:

In a big pot there are 100 balls. Out of these 100 balls 50 balls are white and 50 balls are black. By chance, one single ball is drawn out of the pot. If this ball is white you get the higher payoff. If the ball is black you get the lower payoff.

For example, if the lottery is a lottery in which you can earn either 5 or 10 Euro, you can imagine the following: If a white ball is drawn out of the pot with 100 balls, you will receive 5 Euro. If a black ball is drawn out of the pot with 100 balls, you will receive 10 Euro. 


\section{Decision process}

After you have been offered a lottery within the experiment, we ask you which fixed amount of money we would have to offer you so that you are willing to abstain from participating in the lottery. Your decision between the participation in the lottery and the fixed amount of money is taken according to a procedure that will be explained to you in detail in the following.

Let us assume - like in the example above - that you can receive either 5 or 10 Euro in the lottery. The chance that you receive 5 Euro is thereby as big as the chance that you receive 10 Euro. Please note that this lottery is only an example. It does not show up in the experiment!

First of all we ask you whether you would abstain from participating in the lottery if you could receive a fixed amount of money of 7.50 Euro instead. If you prefer receiving 7.50 Euro to participating in the lottery, then click on "yes". If you prefer participating in the lottery to receiving 7.50 Euro, then click on "no".

The next question is very similar to the first one. The only difference is that now you are not offered 7.50 Euro but another fixed amount of money. For example, we offer you 8.75 Euro or 6.25 Euro in the second step. We then again ask you whether you would be ready to abstain from the lottery for a fixed amount of money of 8.75 Euro or 6.25 Euro, respectively. If you prefer receiving this amount of money to participating in the lottery, then click on "yes". If you prefer participating in the lottery to receiving 8.75 Euro or 6.25 Euro, respectively, then click on "no".

These questions are repeated according to this schema several times, whereat we offer you different fixed amounts of money. All these amounts of money are at least as big as the lower payoff of the lottery. And they are not exceeding the higher payoff of the lottery. For the lottery in the example, in which you either receive 5 or 10 Euro, this means: The fixed amounts of money that we offer you for abstaining from the lottery vary between 5 and 10 Euro.

In the first lottery in the experiment we would only like to know for which fixed amount of money you would be ready to abstain from the lottery. However, in any case, you participate in the lottery.

In the second lottery you can effectively abstain from your participation in the lottery. You then receive a fixed amount of money. For this purpose we identify the price against which we "exchange" the lottery. This is done according to a certain mechanism which is explained in the following paragraph.

Determination of the exchange price

First, the computer randomly determines the price for which we exchange the lottery. This price lies in the same range as the amounts of money you are offered during the decision process. For the lottery in the example, this means that the price lies in the range between 5 and 10 Euro.

All amounts in this range have the same chance to be drawn as exchange price. This means the chance that the price is 6.00 Euro is just as high as the chance that it is 8.43 Euro. But it also means that the chance that the price is above 8.43 Euro is far smaller than the chance that it is above 6.00 Euro. This is because there are far more possible prices between 6.00 Euro and 10.00 Euro than between 8.43 Euro and 10.00 Euro. 
The decisive question is then the following: In the decision process, did you abstain from the lottery at an amount which was below or just as high as the price? If yes, you will receive the price and not participate in the lottery. If not, you will not receive the price, but participate in the lottery. You will then receive the low or the high payoff with equal chance.

Consider again the lottery in the example, in which you receive either 5 or 10 Euro. Assume that a price of 6.23 Euro is drawn. When asked whether you wanted to abstain from the lottery for an amount of 6.23 Euro or less - did you choose the fixed amount? Then you will receive 6.23 Euro and not participate in the lottery. Did you choose the lottery? Then you will not receive the 6.23 Euro. You will participate in the lottery and have equal chances to receive 5 or 10 Euro.

Note! If you do not participate in the lottery, you do not receive the lowest amount at which you abstained from the lottery. You receive the price that the computer draws randomly. This means that all participants in the experiment who do not participate in the lottery receive the same amount of money! This means that your choice to abstain from the lottery in exchange for a certain fixed amount does not determine the size of the fixed amount you receive. It determines the chance that you receive the price that the computer determines, rather than to participate in the lottery. If you abstain from the lottery at lower amounts, you increase the chance to receive the price and do not participate in the lottery. If you abstain from the lottery only at higher amounts, you increase the chance to not receive the price but participate in the lottery.

The described mechanism is called Becker-DeGroot-Marshak mechanism. With this mechanism it is optimal for you to state honestly for every fixed amount whether you prefer to participate in the lottery or to receive the fixed amount.

We will now give you more examples of the mechanism.

Example 1:

You can participate in a lottery in which you have equal chances to either have to pay 2 Euro or receive 12 Euro. You decided to abstain from the lottery for all fixed amounts higher than or equal to 3 Euro. For fixed amounts below 3 Euro you preferred to participate in the lottery.

1. The computer randomly draws a price of 4.50 Euro. Since for this amount you decided to abstain from the lottery you receive the price of 4.50 Euro and do not participate in the lottery. 2. The computer randomly draws a price of 1.35 Euro. Since for this amount you preferred to participate in the lottery, you do not receive the price. You participate in the lottery, and either pay 2 Euro or receive 12 Euro. Both with equal chance.

Example 2:

You can again participate in a lottery in which you have equal chances to either have to pay 2 Euro or receive 12 Euro. You decided to abstain from the lottery for all fixed amounts higher than -0.50 Euro. For fixed amounts below -0.50 Euro you preferred to participate in the lottery.

1. The computer randomly draws a price of -0.70 Euro. For this amount you preferred to participate in the lottery and not receive the fixed amount. Accordingly, 
you do not pay the price of 0.70 Euro. You participate in the lottery, and either pay 2 Euro or receive 12 Euro. 2. The computer randomly draws a price of -0.35 Euro. For this amount you decided to rather pay the price and abstain from the lottery. Accordingly, you pay the price of 0.35 Euro and do not participate in the lottery.

As mentioned before, the exchange price is only drawn for your decision regarding the second lottery. For the first lottery you merely complete the decision process as described above. You will complete this decision process in two more parts of the experiment. The decisions you have to make there are described in detail in due time.

Please complete now carefully the questions below, to ensure that you understood the described procedures. 


\section{References}

Abel, A., 1990: Asset Prices under Habit Formation and Catching up with the Joneses, The American Economic Review, Vol. 80, No. 2, Papers and Proceedings of the Hundred and Second Annual Meeting of the American Economic Association, 38-42.

Akerlof, G. and Kranton, R., 2000: Economics and Identity, Quarterly Journal of Economics, Vol. 115(3), 715-753.

Bandura, A., Barbaranelli, C., Caprara, G.V. and Pastorelli, C., 2001: SelfEfficacy Beliefs as Shapers of Children's Aspirations and Career Trajectories, Child Development, Vol. 72(1), 187-206.

Bryce, W. and Olney, T.J., 1991: Gender Differences in Consumption Aspirations: A Cross-cultural Appraisal, Social Behavior and Personality, Vol. 19(4), 237-253.

Campbell, J. and Cochrane, J., 1999: By Force of Habit: A Consumption-Based Explanation of Aggregate Stock Market Behavior, Journal of Political Economy, Vol. 107(2), April 1999.

Fischbacher, U., 1999: "z-Tree: A Toolbox for Readymade Economic Experiments", Working Paper No. 21, University of Zurich.

Gomes, F. and Michaelides, A., 2003: Portfolio Choice with Internal Habit Formation: A Life-Cycle Model with Uninsurable Labour Income Risk, CEPR Discussion Paper No. 3868.

Hsee, C. and Hastie, R., 2006: Decision and Experience: why don't we chose what makes us happy?, Trends in Cognitive Science, 10 (1), 31-37.

Huck, S., Konrad, K., Normann, H. and Mller, W., 2007: The Merger Paradox and Why Aspiration Levels Let It Fail in the Laboratory, Economic Journal (forthcoming)

Kahneman, D., Tversky, A., 1979: Prospect Theory: An Analysis of Decision under risk, Econometrica, Vol. 47, No. 2, p. 263-292.

Kahneman, D., Krueger, A., Schkade, D., Schwarz, N., and Stone, A., (2006): Would You Be Happier If You Were Richer? A Focusing Illusion, Science, 312 (5782), 1908-1910.

Köszegi, B., Rabin, M., 2006: A Model of Reference-dependent Preferences, Quarterly Journal of Economics, Vol. 121(4), 1133-1165.

Lopes, L. and Oden, G.C., 1999: The Role of Aspiration Level in Risky Choice: A Comparison of Cumulative Prospect Theory and SP/A Theory, Journal of Mathematical Psychology, Vol. 43, 286-313.

Matthey, A. 2006, Getting Used to Expectations, Working Paper, Technical University Berlin.

McBride, M., 2007: Money, Happiness, and Aspirations: An Experimental Study, University of California-Irvine, Departmennt of Economics Working Papers 060721.

Nauta, M., Epperson, D.L. and Kahn, J., 1998: A Multiple-Groups Analysis of Predictors of Higher Level Career Aspirations Among Women in Mathematics, 
Science, and Engineering Majors, Journal of Counseling Psychology, Vol. 45(4), 483-496.

Ng, Y. and Wang, J., 2001: Attitude choice, economic change, and welfare, Journal of Economic Behavior and Organization, Vol. 45, 279-291.

Pinquart, M., Juang, L.P., and Silbereisen, R.K., 2004: The Role of Self-Efficacy, Academic Abilities, and Parental Education in the Change in Career Decisions of Adolescents Facing German Unification, Journal of Career Development, Vol. $31(2), 125-142$.

Sagi, J., 2006: Anchored Preference Relations, Journal of Economic Theory, 130(1), 283-95.

Sauermann, H. and Selten, R., 1962: Anspruchsanpassungstheorie der Unternehmung, Zeitschrift für die gesamte Staatswissenschaft, Vol 118(4).

Selten, R., 1998: Aspiration Adaptation Theory, Journal of Mathematical Psychology, Vol. 42, 191-214.

Shalev, J. (2000), Loss Aversion Equilibrium, International Journal of Game Theory, 29,2 .

Simon, H., 1959: Theories of decision making in economics and behavioral science, American Economic Review, Vol. 49, 253-283.

Staw, B.M., 1976: Knee-deep in the big muddy: A study of escalating commitment to a chosen course of action. Organizational Behavior and Human Performance, Vol. 16, 27-44.

Stutzer, A., 2004: The role of income aspirations in individual happiness, Journal of Economic Behavior and Organization, Vol. 54(1), 89-109.

Thaler, R. H. and Johnson, E.J., 1990, Gambling with the house money and trying to break even: The effects of prior outcomes on risky choice, Management Science, Vol, 36 (6). 643-660.

van Osch, S. M.C., van den Hout, W.B. and Stiggelbout, A.M., 2006: Exploring the Reference Point in Prospect Theory: Gambles for Length of Life, Medical Decision Making 2006, Vol. 26, 338-346.

Weber, M. and Zuchel, H., 2005: How Do Prior Outcomes Affect Risk Attitude? Comparing Escalation of Commitment and the House-Money-Effect, Decision Analysis, Vol. 2 (1), 30-43. 


\section{SFB 649 Discussion Paper Series 2008}

For a complete list of Discussion Papers published by the SFB 649, please visit http://sfb649. wiwi. hu-berlin.de.

001 "Testing Monotonicity of Pricing Kernels" by Yuri Golubev, Wolfgang Härdle and Roman Timonfeev, January 2008.

002 "Adaptive pointwise estimation in time-inhomogeneous time-series models" by Pavel Cizek, Wolfgang Härdle and Vladimir Spokoiny, January 2008.

003 "The Bayesian Additive Classification Tree Applied to Credit Risk Modelling" by Junni L. Zhang and Wolfgang Härdle, January 2008.

004 "Independent Component Analysis Via Copula Techniques" by Ray-Bing Chen, Meihui Guo, Wolfgang Härdle and Shih-Feng Huang, January 2008.

005 "The Default Risk of Firms Examined with Smooth Support Vector Machines" by Wolfgang Härdle, Yuh-Jye Lee, Dorothea Schäfer and Yi-Ren Yeh, January 2008.

006 "Value-at-Risk and Expected Shortfall when there is long range dependence" by Wolfgang Härdle and J ulius Mungo, Januray 2008.

007 "A Consistent Nonparametric Test for Causality in Quantile" by Kiho Jeong and Wolfgang Härdle, January 2008.

008 "Do Legal Standards Affect Ethical Concerns of Consumers?" by Dirk Engelmann and Dorothea Kübler, January 2008.

009 "Recursive Portfolio Selection with Decision Trees" by Anton Andriyashin, Wolfgang Härdle and Roman Timofeev, January 2008.

010 "Do Public Banks have a Competitive Advantage?" by Astrid Matthey, January 2008.

011 "Don't aim too high: the potential costs of high aspirations" by Astrid Matthey and Nadja Dwenger, January 2008. 